\title{
Fine Tuning of the Dimensionality of Zinc Silicate Nanostructures and Their Application as Highly Efficient Absorbents for Toxic Metal Ions
}

\author{
Yan Yang ${ }^{1,2}$, Yuan Zhuang ${ }^{1}$, Yunhua $\mathrm{He}^{2}$, Bo Bai ${ }^{2}$, and Xun Wang ${ }^{1}(\varangle)$ \\ ${ }^{1}$ Department of Chemistry, Tsinghua University, Beijing 100084, China \\ ${ }^{2}$ College of Environmental Science and Engineering, Chang'an University, Xi' an 710054, China \\ Received: 25 February 2010 / Revised: 14 May 2010 / Accepted: 28 June 2010 \\ C The Author(s) 2010. This article is published with open access at Springerlink.com
}

\begin{abstract}
The controllable synthesis of materials with the desired crystal structure and dimensionality is of great significance in material science. In this work we report the successful synthesis of amorphous and crystalline zinc silicates with different dimensionalities and well-defined shapes, including hollow spheres, nanowires and membranes. The structure-related absorption properties have been studied. A detailed study of their ability to remove $\mathrm{Pb}(\mathrm{II}), \mathrm{Cd}(\mathrm{II}), \mathrm{Cr}(\mathrm{III})$, and $\mathrm{Fe}(\mathrm{III})$ ions has been performed. The amorphous zero-dimensional (0-D) hollow spheres show the best removal ability for all the metal ions investigated. In particular, their absorption capacity for $\mathrm{Pb}(\mathrm{II})$ ions is $129 \mathrm{mg} / \mathrm{g}$, which is double the value reported for magnesium silicate hollow spheres. However, the removal abilities of crystalline one-dimensional (1-D) nanowires and two-dimensional (2-D) membranes are found to be dependent on the charge of the target metal ion. In general, nanowires show better removal capacity for trivalent ions, especially Fe(III), while 2-D membranes exhibit better removal capacity for divalent ions.
\end{abstract}

\section{KEYWORDS}

Hollow spheres, nanowires, membranes, absorbent

\section{Introduction}

Solid materials with different spatial arrangements of the same atoms may have quite different physicochemical properties. Taking carbon materials as an example, diamond with its atomic crystal is a hard material, while soft and conductive graphite is a transition crystal between atomic, metal and molecular crystals with its layered structure held together by van der Waals forces. In addition, amorphous carbon materials with porous structures-for example active carbon-exhibit excellent adsorption properties [1-3].
From the viewpoint of the dimensionalities of materials, zero-dimensional (0-D) fullerenes, 1-D carbon nanotubes (CNTs), and 2-D graphene have their own unique properties [4-15]. Such considerations show that the crystal structure and dimensionality usually determine the properties and applications of materials. Controllable synthesis of materials with the desired crystal structure and dimensionality is of great significance and the subject of considerable research. In this paper we demonstrate the fine tuning of the dimensionality of zinc silicate, as well as the structurerelated absorption properties of the resulting materials. 
For many years, silicates have attracted great attention due to their special physicochemical properties, low cost and abundant supply, and have been widely applied in many fields, such as molecular sieves [16-18], catalyst supports [19-22], gas absorption and separation [23, 24], and as raw materials for the glass industry. Examples of 1-D zinc silicates with different morphologies-including needle-like [25], nanowires [26, 27], rice-like [28], and nanorod-like [29-32] - have been synthesized by hydrothermal methods. However, 0-D hollow spheres and 2-D membrane nanostructures have been scarcely reported.

In this work, we have successfully synthesized zinc silicate with tunable dimensionalities using different systems. In an ethanol/polyethylene glycol (PEG) system, 0-D hollow spheres with an amorphous structure were obtained. In aqueous systems, both 1-D nanowires and 2-D membranes with crystalline structures were prepared by controlling the ratio of zinc to silicon and the amount of mineralizer. Since silicates are low cost in comparison with other nanostructured absorbents such as iron-based nanoabsorbents [33,34], $\mathrm{CeO}_{2}$ supported on CNTs [35], and layered titanate nanofibers [36], the prepared zinc silicate samples were used as absorbents to remove toxic metal ions. Compared with magnesium silicate hollow spheres, which we have reported previously [37], the amorphous zinc silicate hollow spheres show better removal capacity for $\mathrm{Pb}(\mathrm{II}), \mathrm{Cd}(\mathrm{II}), \mathrm{Cr}(\mathrm{III})$, and $\mathrm{Fe}(\mathrm{III})$ ions in aqueous solution.

\section{Experimental}

\subsection{Chemicals}

All reagents were of analytical grade and purchased from Beijing Chemicals Co. (Beijing, China) and used without further purification. Deionized water was used throughout.

\subsection{Preparation of zinc silicate hollow spheres}

Zinc silicate hollow spheres were prepared hydrothermally in an ethanol/PEG mixed solvent system. In a typical procedure, $1 \mathrm{~mL}$ of $0.2 \mathrm{~mol} / \mathrm{L} \mathrm{Zn}\left(\mathrm{NO}_{3}\right)_{2}$ solution was well mixed with ethanol $(30 \mathrm{~mL})$ and PEG200 (3 mL) and then $1 \mathrm{~mL}$ of $0.2 \mathrm{~mol} / \mathrm{L} \mathrm{Na}_{2} \mathrm{SiO}_{3}$ solution was added with magnetic stirring, giving a white precipitate. After 10 min of continuous magnetic stirring, $0.1 \mathrm{~mL}$ of $4 \mathrm{~mol} / \mathrm{L} \mathrm{NaOH}$ was added to the mixture which was stirred for a further $15 \mathrm{~min}$. The mixture was sealed in a Teflon-lined autoclave and treated hydrothermally at $190{ }^{\circ} \mathrm{C}$ for $12 \mathrm{~h}$. The asobtained precipitate was centrifuged and washed three times with deionized water and once with ethanol to remove any remaining ions and PEG. Finally, the product was dried at $70{ }^{\circ} \mathrm{C}$ in air or dispersed in ethanol for the preparation of TEM samples.

\subsection{Synthesis of nanowires}

Zinc silicate with a 1-D nanowire morphology was obtained in an aqueous system by controlling the amount of sodium silicate. In a typical synthesis, $2 \mathrm{mmol}$ of $\mathrm{Zn}\left(\mathrm{NO}_{3}\right)_{2}$ was dissolved in $10 \mathrm{~mL}$ of deionized water and 1.1-1.2 $\mathrm{mL}$ of ammonia solution (25\%) was added drop by drop to form first a white precipitate and then a transparent solution of complex ions. An additional $20 \mathrm{~mL}$ of water was added dropwise. $3 \mathrm{~mL}$ of $0.5 \mathrm{~mol} / \mathrm{L} \mathrm{Na}_{2} \mathrm{SiO}_{3}$ was added with magnetic stirring for $15 \mathrm{~min}$. Finally, $2 \mathrm{~g}$ of $\mathrm{NaCl}$ was added and the mixture stirred for a further $15 \mathrm{~min}$. The mixture was sealed in a Teflon-lined autoclave, heated to $200{ }^{\circ} \mathrm{C}$ and maintained at that temperature for $12 \mathrm{~h}$.

\subsection{Preparation of membranes}

Zinc silicate with a 2-D membrane morphology was obtained in an aqueous system. $2 \mathrm{mmol}$ of $\mathrm{Zn}\left(\mathrm{NO}_{3}\right)_{2}$ was dissolved in $10 \mathrm{~mL}$ of deionized water and 1.1-1.2 $\mathrm{mL}$ of ammonia solution (25\%) was added drop by drop to form first a white precipitate and then a transparent solution of complex ions. Then an additional $20 \mathrm{~mL}$ of water was added dropwise. Finally, $5 \mathrm{~mL}$ of $0.5 \mathrm{~mol} / \mathrm{L}$ of $\mathrm{Na}_{2} \mathrm{SiO}_{3}$ solution was added and the mixture stirred for $15 \mathrm{~min}$. The mixture was then sealed in a Teflon-lined autoclave and treated hydrothermally at $200{ }^{\circ} \mathrm{C}$ for $12 \mathrm{~h}$.

\subsection{Ion exchange experiments}

To obtain $\mathrm{Pb}(\mathrm{II}), \mathrm{Cd}(\mathrm{II}), \mathrm{Cr}(\mathrm{III})$, and $\mathrm{Fe}(\mathrm{III})$ ion solutions, $\mathrm{Pb}\left(\mathrm{NO}_{3}\right)_{2}, \mathrm{Cd}\left(\mathrm{NO}_{3}\right)_{2} \cdot 4 \mathrm{H}_{2} \mathrm{O}, \mathrm{CrCl}_{3} \cdot 6 \mathrm{H}_{2} \mathrm{O}$, and $\mathrm{Fe}\left(\mathrm{NO}_{3}\right)_{3} \cdot 9 \mathrm{H}_{2} \mathrm{O}$ were used as precursors. The $\mathrm{pH}$ of 
solutions containing the above metal ions was adjusted to 2 by addition of dilute nitric acid $(v / v=1 / 10)$ to avoid hydrolysis of the metal ions. For all of the ion exchange experiments, $50 \mathrm{mg}$ of zinc silicate absorbent was ultrasonically dispersed in $10 \mathrm{~mL}$ of deionized water and the $\mathrm{pH}$ was tuned to 7.0 . Then $10 \mathrm{~mL}$ of the solution containing metal ions was added to the mixture which was magnetically stirred for $3 \mathrm{~h}$. Finally, the solid and liquid were separated by centrifugation and the concentration of metal ions in the solution was measured by inductively coupled plasma optical emission spectroscopy. A control experiment was carried out by replacing the solutions containing metal ions with deionized water with the $\mathrm{pH}$ adjusted in the same way.

\subsection{Characterization}

The morphology and phase purity of as-obtained samples were determined using a FEI Tecnai G2 F20 S-Twin high-resolution transmission electron microscope (HRTEM) with an acceleration voltage of $200 \mathrm{kV}$ and equipped with an energy dispersive $\mathrm{X}$-ray (EDX) detector. Powder X-ray diffraction (XRD) patterns were recorded on a Bruker D8 Advance X-ray diffractometer using $\mathrm{Cu} \mathrm{K} \alpha$ radiation $(\lambda=1.5418 \AA$ ) $)$. Phase stability was characterized by thermogravimetric analysis (TGA) and differential thermal analysis (DTA) using a Mettler Toledo 851e instrument. The specific surface areas were obtained by the Brunauer-Emmett-Teller (BET) method based on nitrogen adsorption/desorption measurements (Micromeritics ASAP 2010C). The concentration of $\mathrm{M}^{n+}$ in aqueous solution was obtained by the inductively coupled plasma (ICP) technique using a IRIS Intrepid II XSP ICP-OES.

\section{Results and discussion}

\subsection{Zinc silicate nanostructures with different dimensionalities}

Zinc silicate hollow spheres, nanowires and membranes were successfully synthesized using hydrothermal methods. Figures 1(a) and 1(b) show scanning electron microscope (SEM) and transmission electron microscope (TEM) images of pure 0-D hollow spheres which have an outer diameter of 50-200 nm. Magnified TEM images show that the wall thickness is about $20 \mathrm{~nm}$ (Figs. 1(c) and 1(d)). Furthermore, no evidence of a crystal lattice was found in HRTEM studies, indicating that the hollow spheres are amorphous
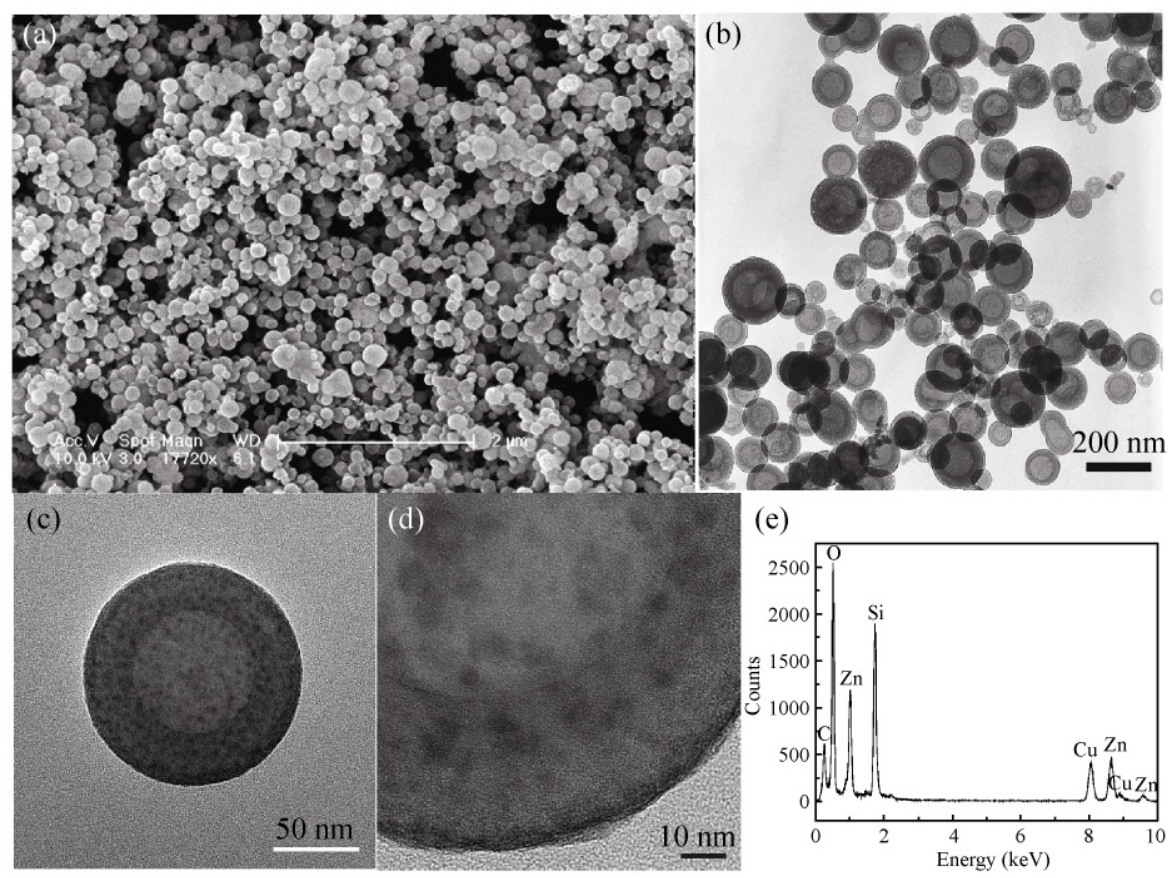

Figure 1 Images of zinc silicate hollow spheres: (a) SEM; (b) TEM; (c) and (d) HRTEM; (e) energy dispersive spectrum (EDS) pattern

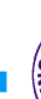


in nature. Further evidence for an amorphous structure is provided by XRD measurements which show no sharp reflections, and only one broad reflection (Fig. 4(a)).

Figures 2(a) and 2(b) show that the 1-D nanowires interweave together to form bundle-like structures. An HRTEM image (Fig. 2(d)) reveals three types of lattice spacing of about $0.2600 \mathrm{~nm}, 0.3125 \mathrm{~nm}$, and $0.3277 \mathrm{~nm}$ as calculated by fast Fourier transform (FFT), corresponding to (002), (211), and (130) planes, respectively. Nanowires with truncated polyhedral tails result from this kind of preferential growth as shown in Fig. 2(c).

Figures 3(a) and 3(b) show TEM images of pure zinc silicate membranes. The membranes have a layered structure with an interlamellar spacing of $1.28 \mathrm{~nm}$ as

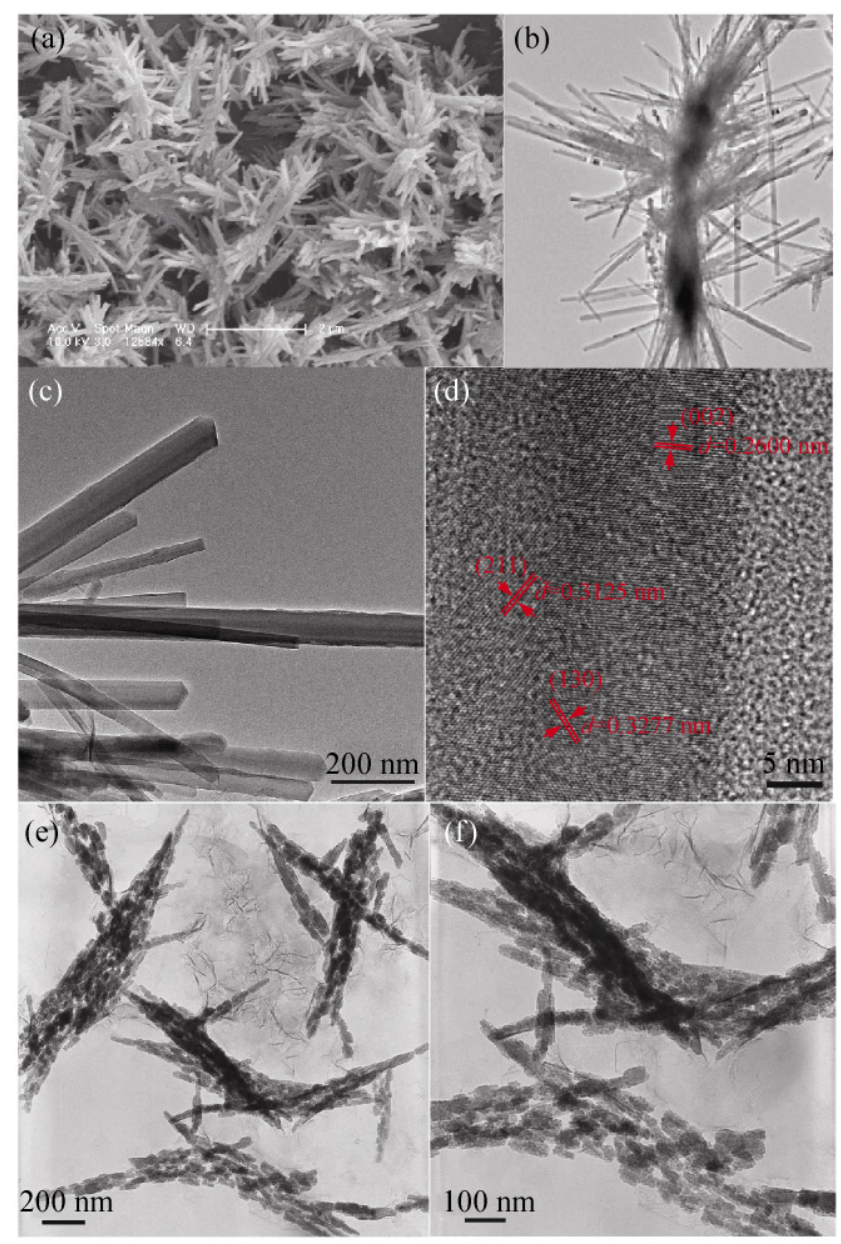

Figure 2 Images of zinc silicate with a 1-D nanowire morphology: (a) SEM; (b), (c) TEM and (d) HRTEM images of the product obtained with addition of $\mathrm{NaCl}$; (e), (f) TEM images of the product obtained without addition of $\mathrm{NaCl}$ shown in the HRTEM image in Fig. 3(c). The layered structure of the membranes is further confirmed by the low angle XRD pattern (Fig. 3(d)). There is a strong peak with a $2 \theta$ value of $6.9^{\circ}$ corresponding to $d=1.28 \mathrm{~nm}$. In conclusion, 0-D hollow spheres, 1-D nanowires, and 2-D membranes have been successfully synthesized.

The phase purity of the zinc silicates was characterized by XRD. As noted above, the amorphous structure of the hollow spheres is confirmed by the XRD pattern shown in Fig. 4(a). The EDS confirms that zinc and silicon coexist in the sample (Fig. 1(e)) even after the sample was extensively washed to ensure that no zinc ions remained physisorbed. Therefore we believe that amorphous zinc silicate has been successfully synthesized in the ethanol/PEG system.

The XRD pattern (Fig. 4(c)) of the nanowires can be indexed to the orthorhombic phase of $\mathrm{Zn}_{4} \mathrm{Si}_{2} \mathrm{O}_{7}(\mathrm{OH})_{2} \cdot \mathrm{H}_{2} \mathrm{O}$ (space group Imm2 (No. 44)) with lattice spacings of $a=0.837 \mathrm{~nm}, b=1.072 \mathrm{~nm}$, and $c=$ $0.512 \mathrm{~nm}$ (JCPDS 05-0555). The XRD pattern shown in Fig. 4(b) shows that the membranes also consist of the orthorhombic phase of $\mathrm{Zn}_{4} \mathrm{Si}_{2} \mathrm{O}_{7}(\mathrm{OH})_{2} \cdot \mathrm{H}_{2} \mathrm{O}$. Because it is 2-D nanostructure and the membranes are very thin, some peaks are relatively broad. Therefore both amorphous and crystalline zinc silicate samples have been obtained.

As shown in Fig. 5(a), the $\mathrm{Zn}$ and $\mathrm{Si}$ atoms in zinc silicate are arranged in layers along the $z$-axis and each is tetrahedrally coordinated by four oxygen atoms. Two zinc-oxygen or silicon-oxygen tetrahedra link with each other by oxygen bridges to form 8-, 4-, and 6-membered rings, with water molecules existing in the resulting pores. Some oxygen positions are occupied by hydroxide groups. Generally the nanostructures grow along the $z$-direction to form 1-D nanowires and additional growth in the $x$ - and $y$-directions results in membranes. A ball-and-stick model is shown in Fig. 5(b). For the nanowires, one can see that the main growth direction is the (002) zone axis orientation (Fig. 5(c)), consistent with the HRTEM results (Fig. 2(d)).

The stability of the crystalline zinc silicate phases was characterized by thermogravimetric analysis under a nitrogen atmosphere. For the membranes (Fig. 6(a)), there are three obvious weight loss steps and the total 


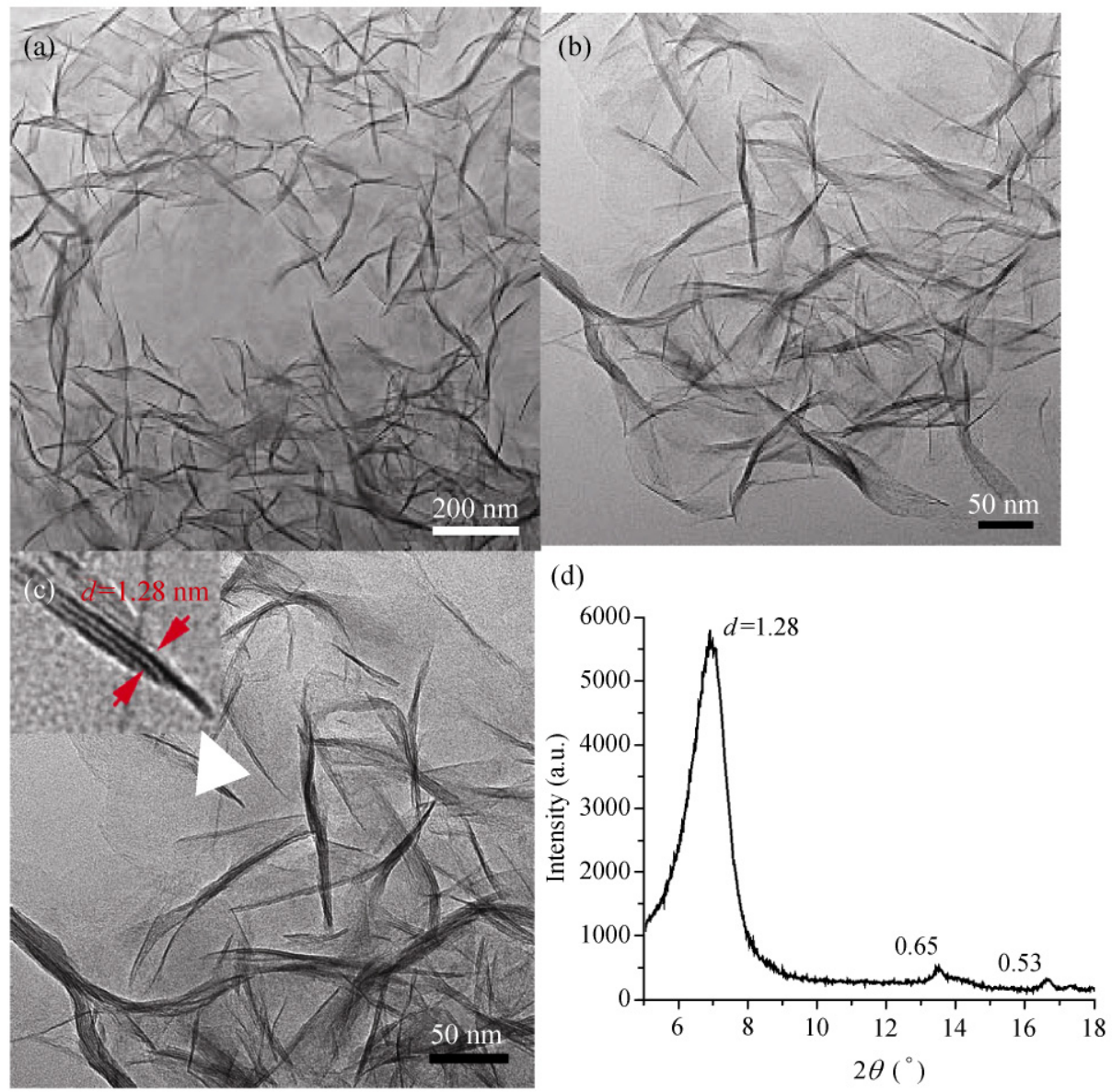

Figure 3 Images of zinc silicate with a 2-D membrane morphology: (a), (b) TEM; (c) HRTEM; (d) Low angle XRD

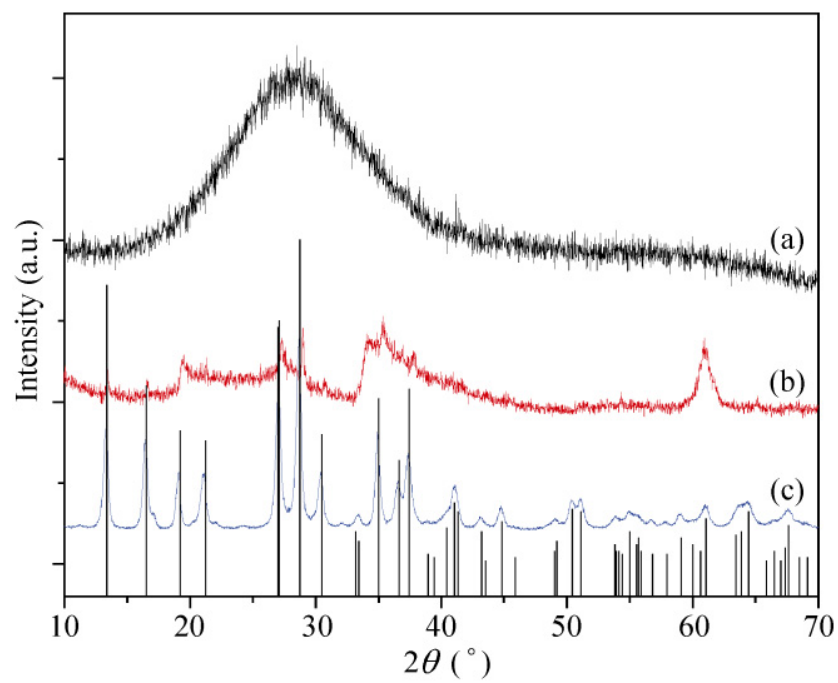

Figure 4 XRDs of zinc silicate samples: (a) hollow spheres; (b) membranes; (c) nanowires

weight loss is about $12 \%$. The first step from room temperature to $110{ }^{\circ} \mathrm{C}$ is an endothermic process that corresponds to the loss of free water; the second step $\left(110-400{ }^{\circ} \mathrm{C}\right)$ corresponds to the removal of water of crystallization; the third step $\left(400-550{ }^{\circ} \mathrm{C}\right)$ represents the loss of water formed by dehydroxylation; above $550{ }^{\circ} \mathrm{C}$, only a small mass loss occurs and the phase is relatively stable. Due to their 1-D nanostructure, the nanowires (Fig. 6(b)) capture less free water and the total weight loss is less than $10 \%$. Below $110{ }^{\circ} \mathrm{C}$, there is just a small weight loss; at $110-400{ }^{\circ} \mathrm{C}$, combined water is lost; at $400-720^{\circ} \mathrm{C}$, water is lost by dehydroxylation. The nanowires lose more combined water (about $8 \%$ by weight) than the membranes (about $5 \%$ by weight).

\subsection{Mechanism of formation of different zinc silicate nanostructures}

Zinc silicate hollow spheres were obtained in an ethanol/PEG200 system. The formation process probably involves the following steps. Firstly, $\mathrm{Zn}$ (II) ions are well dispersed in the mixture of ethanol/PEG200. 
After adding sodium silicate, a precursor of amorphous $\mathrm{SiO}_{2} \cdot x \mathrm{H}_{2} \mathrm{O}$ solid spheres is formed (Fig. S-1(a) in the Electronic Supplementary Material (ESM)) and some $\mathrm{Zn}$ (II) ions become physisorbed on the outer surface of the spheres [37]. When $\mathrm{NaOH}$ is added to the system, $\mathrm{SiO}_{2} \cdot x \mathrm{H}_{2} \mathrm{O}$ reacts with $\mathrm{Zn}$ (II) ions under hydrothermal treatment and is transformed to a stable zinc silicate phase with the assistance of hydroxyl groups on the outer surface of the solid spheres. Meanwhile, $\mathrm{SiO}_{2} \cdot x \mathrm{H}_{2} \mathrm{O}$ in core of the spheres gradually migrates outwards and reacts with $\mathrm{Zn}$ (II) ions to form a stable zinc silicate phase in the alkaline medium. Finally, hollow spheres are obtained. In the process, $\mathrm{SiO}_{2} \cdot x \mathrm{H}_{2} \mathrm{O}$ is not only a physical template, but also acts as a chemical template (Scheme 1).

In the formation of hollow spheres, the amount of $\mathrm{NaOH}$ is a key factor. Controlled experiments indicate that if no $\mathrm{NaOH}$ is added to the system, only solid spheres are formed as shown in Fig. S-1(b) (in the ESM). In addition, if no $\mathrm{Zn}($ II) ions are added to the
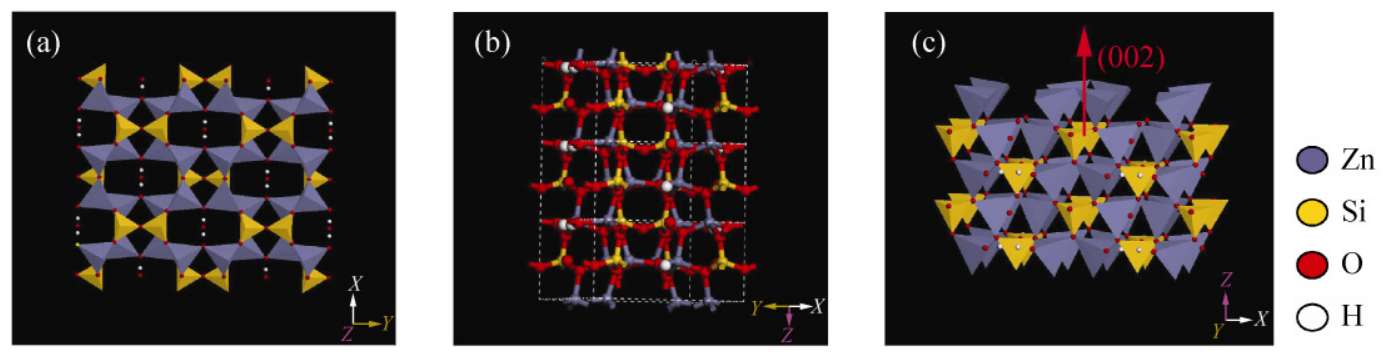

Figure 5 Images of the structure of the $\mathrm{Zn}_{4} \mathrm{Si}_{2} \mathrm{O}_{7}(\mathrm{OH})_{2} \cdot \mathrm{H}_{2} \mathrm{O}$ phase

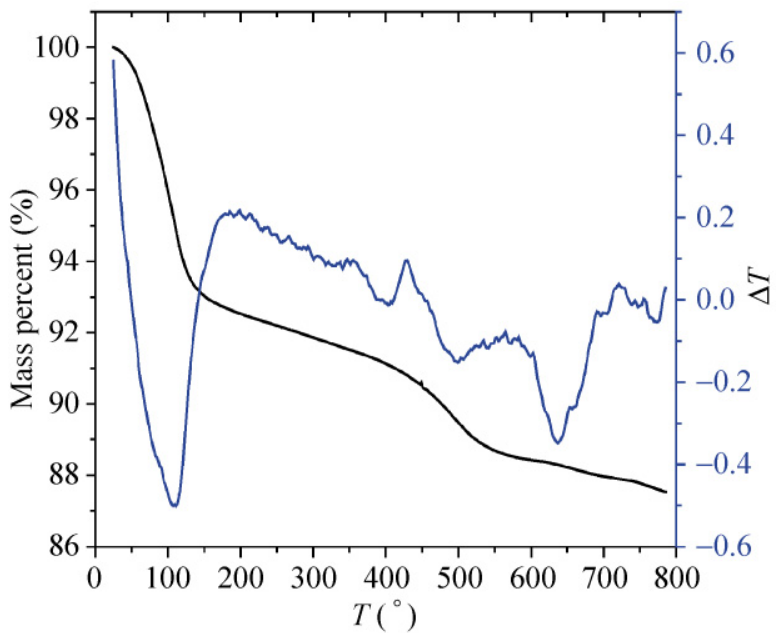

(a)

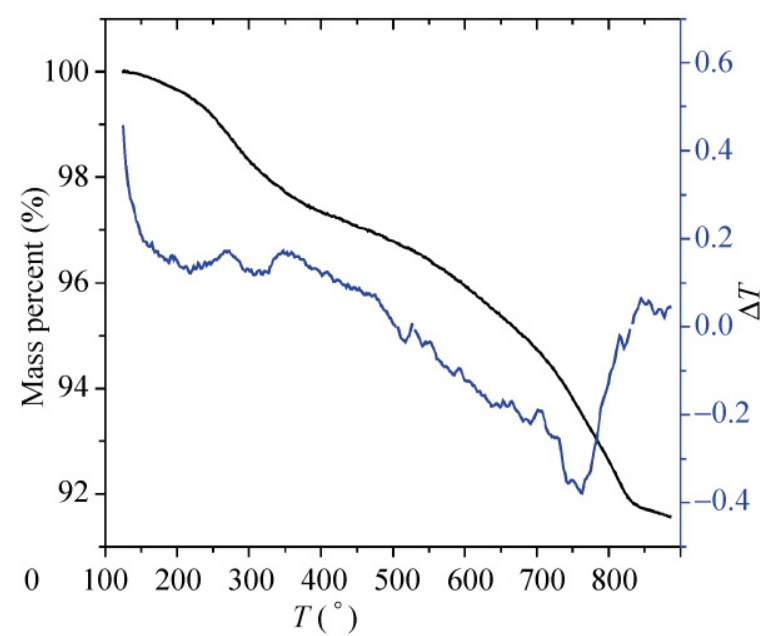

(b)

Figure 6 Thermogravimetric analysis (TGA) and differential thermal analysis (DTA) of zinc silicate: (a) membranes; (b) nanowires

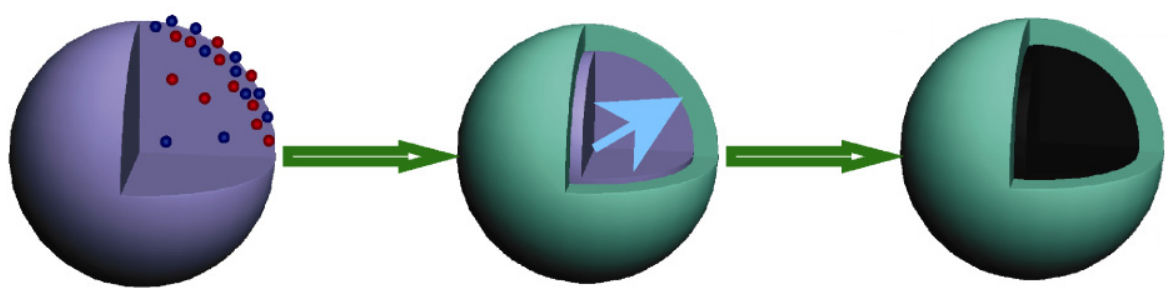

Scheme 1 The process of formation of zinc silicate hollow spheres (the purple sphere represents $\mathrm{SiO}_{2} \cdot x \mathrm{H}_{2} \mathrm{O}$ solid spheres; and the green sphere represents zinc silicate; small red particles represent zinc ions and blue spheres represent hydroxyl groups) 
system, the product is an agglomerate. Figure S-1(c) (in the ESM) shows a TEM image of the solid spheres and the XRD pattern can be indexed to the monoclinic phase of $\mathrm{Na}_{2} \mathrm{Si}_{2} \mathrm{O}_{5}$ with the space group $P 2_{1} / a$ (No. 14) (JCPDS 23-0529) (Fig. S-1(d) in the ESM). These results further confirm that the hollow spheres are a zinc silicate phase rather than a silicon dioxide phase with zinc ions trapped in the amorphous structure by physical adsorption.

The nanowires and membranes are synthesized in aqueous systems, in which an abundance of hydrogen bonds are supplied by water and ammonia which is extremely beneficial to the growth of zinc silicate crystals. The molar ratio of $\mathrm{Zn}$ :Si plays a pivotal role in the synthesis of the nanowires and membranes. Controlled experiments were done by adding a constant amount ( $2 \mathrm{mmol}$ ) of $\mathrm{Zn}(\mathrm{II})$ ions and adding different amounts of $\mathrm{Na}_{2} \mathrm{SiO}_{3}$ into the system. When $1 \mathrm{mmol}$ of $\mathrm{Na}_{2} \mathrm{SiO}_{3}$ was used, SEM and TEM images (Fig. S-2 in the ESM) show that short nanorods were obtained. The XRD pattern indicates that these consist of $\mathrm{Zn}_{4} \mathrm{Si}_{2} \mathrm{O}_{7}(\mathrm{OH})_{2} \cdot \mathrm{H}_{2} \mathrm{O}$ (Fig. S-4(b) in the ESM). When the amount of $\mathrm{Na}_{2} \mathrm{SiO}_{3}$ was increased to $1.5 \mathrm{mmol}$, nanowire bundles began to form (Fig. 2). With a further increase in the amount of $\mathrm{Na}_{2} \mathrm{SiO}_{3}$ to $2.5 \mathrm{mmol}$, membranes were obtained (Fig. 3). When the $\mathrm{Zn}$ :Si ratio was 2:1, 1-D nanostructure clearly began to form. Increasing the amount of $\mathrm{Na}_{2} \mathrm{SiO}_{3}$ giving a $\mathrm{Zn}: \mathrm{Si}$ ratio of $2: 1.5$, resulted in more silicon-oxygen tetrahedra linking with residual zinc-oxygen tetrahedra in the solution, giving rise to further growth of 1-D nanowires. Meanwhile, owing to the strong hydrogen bonding forces from the hydroxide groups and combined water, the nanowires are inclined to cross-connect (Fig. 2(b)). In particular, the addition of more $\mathrm{Na}_{2} \mathrm{SiO}_{3}$ to give a $\mathrm{Zn}: \mathrm{Si}$ ratio of $2: 2.5$ promotes crystal growth along the $x$ - and $y$-planes resulting in the formation of membranes.

In addition, $\mathrm{NaCl}$ plays an important role in the formation of 1-D nanowires, but has no influence on the formation of the $\mathrm{Zn}_{4} \mathrm{Si}_{2} \mathrm{O}_{7}(\mathrm{OH})_{2} \cdot \mathrm{H}_{2} \mathrm{O}$ phase. Under the appropriate conditions for preparing the nanowires, an ordered rod-like product is obtained without addition of $\mathrm{NaCl}$ (Figs. 2(e) and 2(f)). The XRD pattern shows that these are composed of the $\mathrm{Zn}_{4} \mathrm{Si}_{2} \mathrm{O}_{7}(\mathrm{OH})_{2} \cdot \mathrm{H}_{2} \mathrm{O}$ phase (Fig. S-4(a) in the ESM).
Due to the lack of sufficient linking forces, the nanorods cannot further weld to form nanowires although they do attach to each other and become arrayed in the shape of nanowires. According to XRD (Fig. 4(c)) and EDS (Fig. S-3 in the ESM) results, there is no sodium or chlorine-containing phase present in the nanowires. $\mathrm{NaCl}$ merely serves as a mineralizer in the system. It increases the ionic strength and chemical potential which supplies sufficient bonding forces to form 1-D nanowires. The results also reveal that the nanowires do not gradually grow from one specific point into a 1-D structure. The most probable growth mechanism is that short rod-like nanoparticles are first formed in solution, and then adopt an ordered assembly which is converted into highly crystalline nanowires with the assistance of sodium chloride. In the case of the membranes, there is no obvious influence of added $\mathrm{NaCl}$ on their formation.

\subsection{Capacity of as-obtained zinc silicate materials for removal of toxic metal ions}

To investigate the capacity of the as-obtained zinc silicate samples for the removal of toxic metal ions, aqueous solutions containing $\mathrm{Pb}$ (II), $\mathrm{Cd}$ (II), $\mathrm{Cr}$ (III), and $\mathrm{Fe}$ (III) were prepared. As shown in Table 1, hollow spheres are the best absorbent for all the above metal ions. In a typical experiment, $50 \mathrm{mg}$ of hollow spheres were dispersed in $20 \mathrm{~mL}$ of solutions. After static absorption for $3 \mathrm{~h}$ with magnetic stirring, the concentration of $\mathrm{Pb}(\mathrm{II}), \mathrm{Cd}(\mathrm{I})$, and $\mathrm{Fe}(\mathrm{III})$ ions was reduced as shown in Table 1 . For $\mathrm{Cr}$ (III) ions, the removal capacity was $67.5 \mathrm{mg} / \mathrm{g}$. Additionally, since the hollow spheres exhibit good removal capacity for $\mathrm{Pb}(\mathrm{II}), \mathrm{Cd}(\mathrm{II})$ and $\mathrm{Fe}$ (III) ions, these three metal ions were chosen to investigate the selectivity of the hollow spheres. The concentration of $\mathrm{Pb}(\mathrm{II}), \mathrm{Cd}(\mathrm{II})$, and $\mathrm{Fe}(\mathrm{III})$ ions in the same solution could be reduced from $223.14 \mathrm{mg} / \mathrm{L}$, $224.06 \mathrm{mg} / \mathrm{L}$, and $221.68 \mathrm{mg} / \mathrm{L}$ to $128.80 \mathrm{mg} / \mathrm{L}, 219.70$ $\mathrm{mg} / \mathrm{L}$, and $39.65 \mathrm{mg} / \mathrm{L}$, respectively. This result indicates that the hollow spheres exhibit good selectivity for $\mathrm{Fe}$ (III) ions, and show a certain selectivity for $\mathrm{Pb}$ (II) ions. Compared with the hollow spheres, the nanowires and membranes have a lower removal capacity. Using $50 \mathrm{mg}$ of nanowires as absorbent, the removal capacity of $\mathrm{Pb}(\mathrm{II}), \mathrm{Cd}(\mathrm{II})$, and $\mathrm{Cr}(\mathrm{III})$ ions was 48.93 $\mathrm{mg} / \mathrm{g}, 13.22 \mathrm{mg} / \mathrm{g}$, and $59.80 \mathrm{mg} / \mathrm{g}$, respectively. With 
$50 \mathrm{mg}$ of the membranes, the corresponding removal capacity was $59.06 \mathrm{mg} / \mathrm{g}, 44.90 \mathrm{mg} / \mathrm{g}$, and $20.10 \mathrm{mg} / \mathrm{g}$, respectively. In particular, the nanowires exhibited much higher removal capacity for Fe(III) than for other metal ions as shown in Table 1. In general, the nanowires showed better removal capacity for the trivalent ions $\mathrm{Cr}$ (III) and $\mathrm{Fe}(\mathrm{III})$, while the membranes were more effective for removal of the divalent ions $\mathrm{Pb}$ (II) and $\mathrm{Cd}($ II).

Table 1 Capacities of zinc silicate materials with different morphologies for removal of metal ions

\begin{tabular}{ccccc}
\hline \multirow{2}{*}{ Ions } & $\begin{array}{c}\text { Initial conc. } \\
(\mathrm{mg} / \mathrm{L})\end{array}$ & \multicolumn{3}{c}{ Final conc. $(\mathrm{mg} / \mathrm{L})$} \\
\cline { 3 - 5 } & & Hollow spheres & Nanowires & Membranes \\
\hline $\mathrm{Pb}($ II) & 218.95 & 3.62 & 96.63 & 71.30 \\
$\mathrm{Cd}($ III $)$ & 219.35 & 0.70 & 186.30 & 107.10 \\
$\mathrm{Cr}($ III) & 219.20 & 50.48 & 69.70 & 168.90 \\
$\mathrm{Fe}($ III) & 221.35 & $<0.10$ & 0.37 & 87.50 \\
\hline
\end{tabular}

In Fig. 7, it can be clearly seen that the hollow spheres and nanowires both exhibit better removal capacity for $\mathrm{Fe}(\mathrm{III})$ ion than that of membranes. After ionexchange for $3 \mathrm{~h}$ with the membranes, the color of the $\mathrm{Fe}(\mathrm{III})$ ion solution after addition of $0.01 \mathrm{~mol} / \mathrm{L} \mathrm{SCN}^{-}$ ions is just a little less intense than that of the starting solution. In contrast, the solutions treated with hollow spheres and nanowires are almost colorless after addition of $\mathrm{SCN}^{-}$ions, which indicates that almost all of the $\mathrm{Fe}(\mathrm{III})$ ions have been removed; the ICP results were consistent with this conclusion.

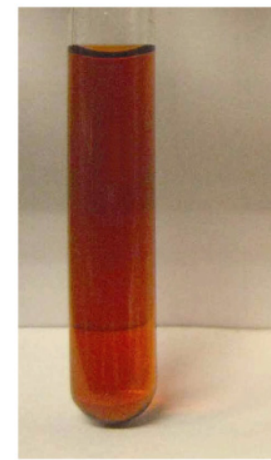

(a)

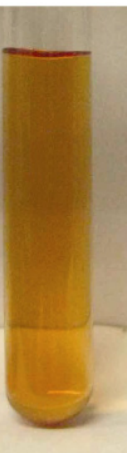

(b)

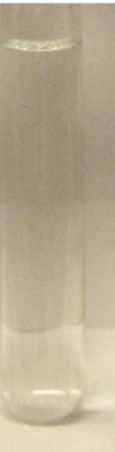

(c)

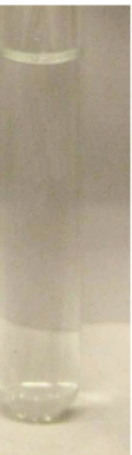

(d)
Figure $7 \mathrm{Fe}(\mathrm{III})$ solutions after addition of $\mathrm{SCN}^{-}$ions: (a) the initial solution $(221.35 \mathrm{mg} / \mathrm{L})$; (b) after exchange with membranes (for $3 \mathrm{~h}$ ); (c) after exchange with hollow spheres (for $3 \mathrm{~h}$ ); (d) after exchange with nanowires (for $3 \mathrm{~h}$ )
The Fe(III) ion solution was chosen to determine the rates of cation removal by the different samples. As shown in Fig. 8, when hollow spheres and nanowires were used as absorbents for only $15 \mathrm{~min}$, the Fe(III) ion solution was colorless on addition of $\mathrm{SCN}^{-}$ions, which means that the concentration has been reduced to less than $4.38 \mathrm{mg} / \mathrm{L}$.

The BET surface area of the zinc silicate hollow spheres is $23 \mathrm{~m}^{2} / \mathrm{g}$, which is much smaller than the value of $355 \mathrm{~m}^{2} / \mathrm{g}$ reported [37] for magnesium silicate hollow spheres. However, the removal capacity (128.62 mg/g) for $\mathrm{Pb}$ (II) ions of zinc silicate hollow spheres is about twice that for magnesium silicate $(64.79 \mathrm{mg} / \mathrm{g})$ for initial solutions with the same concentration of $332.65 \mathrm{mg} / \mathrm{L}$. Obviously, the removal capacity is related to not only BET surface area but also to the crystal structure, and the latter seems to be more important factor. This can be further confirmed by examining the BET surface areas of crystalline zinc silicate samples. The BET surface area of the nanowires $\left(24 \mathrm{~m}^{2} / \mathrm{g}\right)$ is very close to that of the hollow spheres, whereas that for the membranes is much higher $\left(97 \mathrm{~m}^{2} / \mathrm{g}\right)$. However the removal capacity of the membranes is less than that of hollow spheres for all the metal ions studied (Table 1). This confirms that the crystal structure of the product plays an important role in determining the removal capacity.

The amorphous structure of the hollow spheres favors the incorporation of other metal ions into

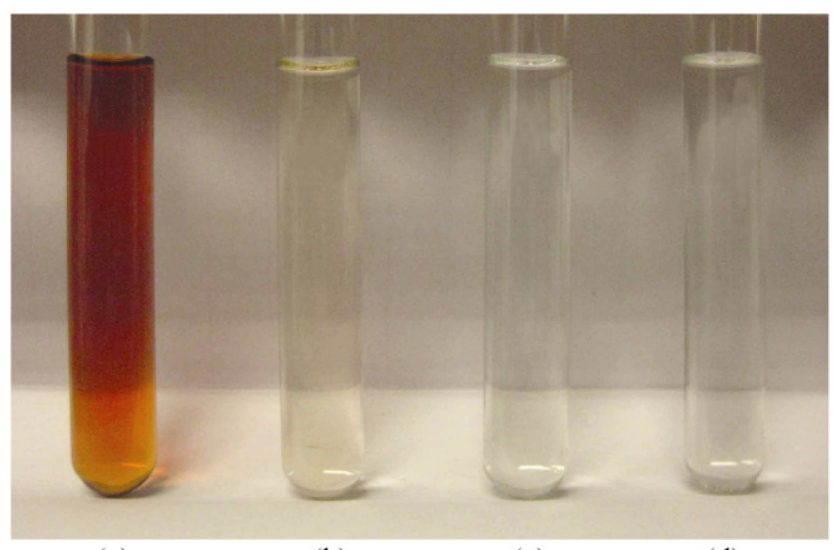

(a)

(b)

(c)

(d)

Figure $8 \mathrm{Fe}$ (III) solutions after addition of $\mathrm{SCN}^{-}$ions: (a) the initial solution $(221.35 \mathrm{mg} / \mathrm{L})$; (b) an $\mathrm{Fe}(\mathrm{III})$ solution with a concentration of $4.38 \mathrm{mg} / \mathrm{L}$; (c) the initial solution after exchange with hollow spheres (for $15 \mathrm{~min}$ ); (d) the initial solution after exchange with nanowires (for $15 \mathrm{~min}$ ) 
vacant sites. As an example, the EDS line scanning analysis of a single hollow sphere exchanged with $\mathrm{Pb}$ (II) ions (Fig. 9(a)) indicates that the $\mathrm{Pb}$ (II) ions are well distributed inside and outside the hollow sphere, which demonstrates that the $\mathrm{Pb}$ (II) ions insert into the vacant sites. For $\mathrm{Pb}$ (II) (and $\mathrm{Cd}(\mathrm{II})$ ions), the oxidation number is the same as that of $\mathrm{Zn}$ (II) and it is relatively easy for them to insert into the vacant positions. However, the radii of $\mathrm{Pb}$ (II) and $\mathrm{Cd}$ (II) ions are $0.121 \mathrm{~nm}$ and $0.097 \mathrm{~nm}$, much larger than that of $\mathrm{Zn}$ (II) ion which is about $0.074 \mathrm{~nm}$. As a result, exchange of these ions with $\mathrm{Zn}$ (II) ions is unfavorable. Therefore the removal capacity of the hollow spheres for $\mathrm{Pb}(\mathrm{II})$ and $\mathrm{Cd}(\mathrm{II})$ ions can be mainly attributed to ion absorption by insertion into the vacant sites in the material. Because the hollow spheres have an amorphous structure there are a large number of available vacant sites, and the hollow spheres show the best removal capacity for $\mathrm{Pb}$ (II) and $\mathrm{Cd}$ (II) ions. The radii of $\mathrm{Cr}$ (III) and $\mathrm{Fe}$ (III) ions are both $0.064 \mathrm{~nm}$, a little smaller than that of the $\mathrm{Zn}$ (II) ion. Therefore these ions can both insert into the vacant sites of the amorphous structure and also partly replace $\mathrm{Zn}$ (II) ions in the hollow spheres. Thus the removal capacity of the hollow spheres for $\mathrm{Cr}$ (III) and $\mathrm{Fe}$ (III) ions can be ascribed to both ion absorption and ion exchange with $\mathrm{Zn}(\mathrm{II})$ ions.

Based on the results of HRTEM and XRD, the exposed crystal faces of zinc silicate nanowires are (211), (130), and (002) with the corresponding lattice spacings of $0.3125 \mathrm{~nm}, 0.3277 \mathrm{~nm}$, and $0.2600 \mathrm{~nm}$, respectively. These lattice spacings are much larger than the radii of $\mathrm{Pb}(\mathrm{II}), \mathrm{Cd}(\mathrm{II}), \mathrm{Cr}(\mathrm{III})$, and $\mathrm{Fe}(\mathrm{III})$ ions, so it is relatively easy for these metal ions to insert into the interstitial voids. As an example, the EDS line scanning analysis of nanowires after exchange with $\mathrm{Pb}$ (II) ions demonstrates that the $\mathrm{Pb}(\mathrm{II})$ ions insert into the structure of the nanowires (Fig. 9(b)). Due to the radii of $\mathrm{Pb}$ (II) and $\mathrm{Cd}(\mathrm{II})$ ions being much larger than $\mathrm{Zn}$ (II) ions, the capacity of nanowires for removal of these ions can be mainly attributed to ion absorption by insertion into the vacant lattice sites in the nanowires. In contrast, for $\mathrm{Cr}$ (III) and $\mathrm{Fe}$ (III) ions, the oxidation number is higher than that of $\mathrm{Zn}$ (II) and the radii are a little smaller than that of the $\mathrm{Zn}$ (II) ion. Therefore exchange of these ions with $\mathrm{Zn}(\mathrm{II})$ is more favorable than filling the vacant lattice positions of the nanowires. Additionally, the exposed crystal faces may favor exchange of $\mathrm{Cr}$ (III) and $\mathrm{Fe}$ (III) ions with $\mathrm{Zn}$ (II) ions. The removal capacity of the nanowires for $\mathrm{Cr}$ (III) and $\mathrm{Fe}$ (III) ions can therefore be ascribed to ion exchange with $\mathrm{Zn}$ (II) ions. Due to the 1-D nanostructure and good crystallinity of the nanowires, there are only a few vacant sites in the product. Hence, the nanowires exhibit lower removal ability for $\mathrm{Pb}(\mathrm{II})$ and $\mathrm{Cd}$ (II) ions than for $\mathrm{Cr}$ (III) and $\mathrm{Fe}(\mathrm{III})$ ions (Table 1).

Because zinc silicate membranes are extremely thin and usually several membranes stack together, the lattice fringes corresponding to the crystal faces cannot

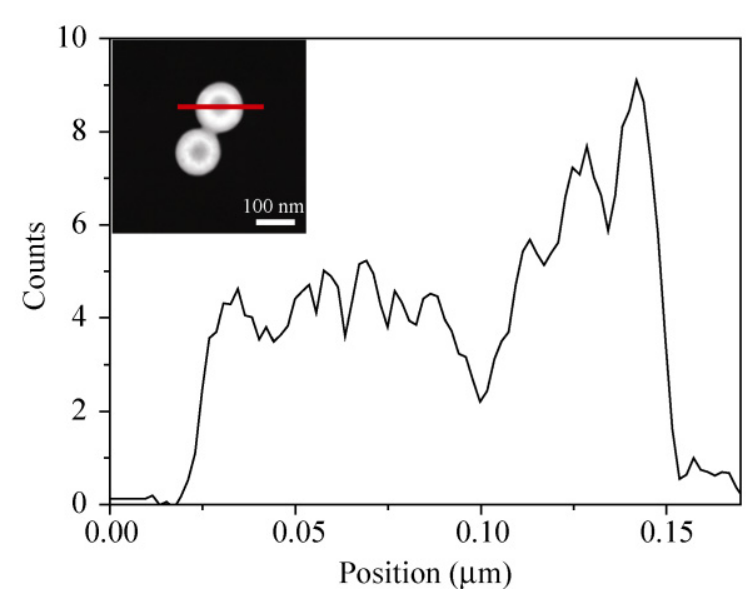

(a)

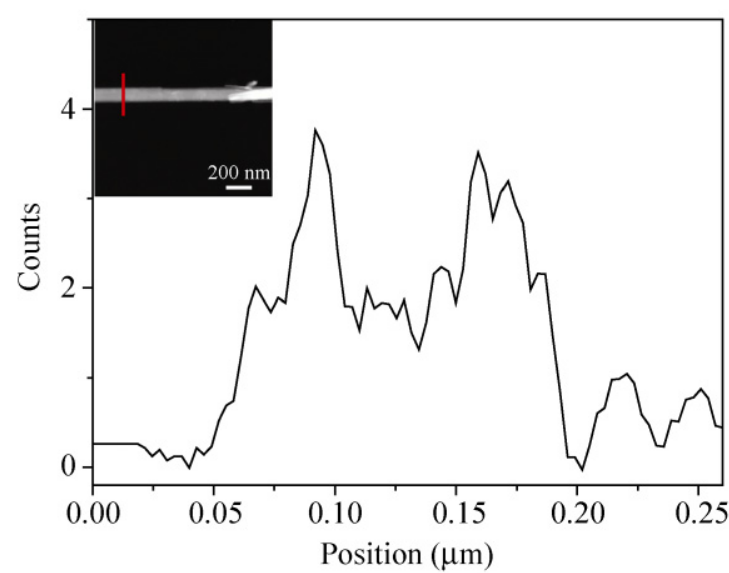

(b)

Figure 9 EDS line scanning analysis for $\mathrm{Pb}$ (along the red line shown in the inset) of zinc silicate nanomaterials after exchange with $\mathrm{Pb}(\mathrm{II})$ ions: (a) hollow spheres; (b) nanowires 
be seen in the HRTEM images. It is difficult to deduce the exposed crystal faces just on the basis of the XRD results. However, as shown in Fig. 3(c), the interlamellar spacing of the membranes is $1.28 \mathrm{~nm}$ which is large enough for the metal ions $(\mathrm{Pb}(\mathrm{II}), \mathrm{Cd}(\mathrm{II}), \mathrm{Cr}(\mathrm{III})$, and $\mathrm{Fe}(\mathrm{III}))$ to insert into the interlamellar galleries. Considering that the membrane is a 2-D nanostructure and very thin, it may have more vacant lattice positions than the 1-D nanowires. In this case, the removal capacity of the membranes for $\mathrm{Pb}$ (II) and $\mathrm{Cd}(\mathrm{II})$ ions will depend mainly on ion absorption by insertion into vacant lattice sites, consistent with the membranes showing better removal ability than the nanowires. The removal capacity of the membranes for $\mathrm{Cr}$ (III) and $\mathrm{Fe}(\mathrm{III})$ ions is lower than that of the nanowires, which maybe because the exposed crystal faces in the membranes do not favor exchange of $\mathrm{Cr}$ (III) and $\mathrm{Fe}(\mathrm{III})$ ions with $\mathrm{Zn}$ (II) ions.

The above hypothesis can be confirmed by determination of the final concentrations of $\mathrm{Zn}$ (II) ions $\left(C_{\mathrm{Zn}}\right)$ in the solutions after ion exchange experiments. In initial control experiments, keeping the other conditions the same as in the ion exchange experiments and just replacing the solutions containing the metal ions by deionized water with a given $\mathrm{pH}$ value, the values of $C_{\mathrm{Zn}}$ for hollow spheres, nanowires and membranes were $6.810 \mathrm{mg} / \mathrm{L}, 52.31 \mathrm{mg} / \mathrm{L}$, and $33.99 \mathrm{mg} / \mathrm{L}$, respectively, at $\mathrm{pH} 2$; the corresponding values of $C_{\mathrm{Zn}}$ at $\mathrm{pH} 4$ were $1.396 \mathrm{mg} / \mathrm{L}, 23.46 \mathrm{mg} / \mathrm{L}$, and $85.95 \mathrm{mg} / \mathrm{L}$, and the values at $\mathrm{pH} 7$ were $0.5563 \mathrm{mg} / \mathrm{L}, 3.385 \mathrm{mg} / \mathrm{L}$, and $107.9 \mathrm{mg} / \mathrm{L}$. These results demonstrate that $\mathrm{Zn}$ (II) ions in the zinc silicates can exchange with protons in an acid medium. As seen in Fig. 10, the values of $C_{\mathrm{Zn}}$ for hollow spheres and nanowires gradually decline with increasing $\mathrm{pH}$ value. In contrast, the membranes show the opposite trend, which results from the residual membranes in the solution. At $\mathrm{pH} 4$ and 7 , there are more hydroxide radicals present in the membranes compared to that at $\mathrm{pH} 2$; these provide more hydrogen bonds with water, and thus it is more difficult for membranes to separate out of the solution at $\mathrm{pH} 4$ and 7 than at $\mathrm{pH} 2$. The higher values of $C_{\mathrm{Zn}}$ for the membranes not only originates from the exchange of $\mathrm{Zn}$ (II) ions with protons but also from the residual membranes in the solution at $\mathrm{pH} 4$ and 7.

The values of $C_{\mathrm{Zn}}$ for hollow spheres, nanowires and membranes in the control experiments at $\mathrm{pH} 2$ $(6.810 \mathrm{mg} / \mathrm{L}, 52.31 \mathrm{mg} / \mathrm{L}$, and $33.99 \mathrm{mg} / \mathrm{L}$, respectively) are very similar to the corresponding values of $C_{\mathrm{Zn}}$ after exchange with $\mathrm{Pb}(\mathrm{II})$ ions (shown in Table 2). Considering that $\mathrm{Zn}(\mathrm{II})$ ions in the zinc silicates can partly exchange with protons at $\mathrm{pH} 2$, it can be concluded that the removal capacity of as-obtained samples for $\mathrm{Pb}(\mathrm{II})$ ions results mainly from ion absorption by insertion into vacant sites. After exchange with $\mathrm{Cd}(\mathrm{II})$ ions, the values of $C_{\mathrm{Zn}}$ (Table 2) are lower than in the control experiments. This indicates that the presence of $\mathrm{Cd}(\mathrm{II})$ ions inhibits the exchange of protons with $\mathrm{Zn}$ (II) ions in the samples to some extent, and the $\mathrm{Cd}$ (II) ions almost always insert into vacant sites.

As shown in Table 2, after stirring the nanowires with $\mathrm{Cr}$ (III) and $\mathrm{Fe}(\mathrm{III})$ ions, the values of $C_{\mathrm{Zn}}$ are higher than the value $(52.31 \mathrm{mg} / \mathrm{L})$ in the control experiment; similarly for the membranes, the values of $C_{\mathrm{Zn}}$ are also higher than the value $(33.99 \mathrm{mg} / \mathrm{L})$ in the control

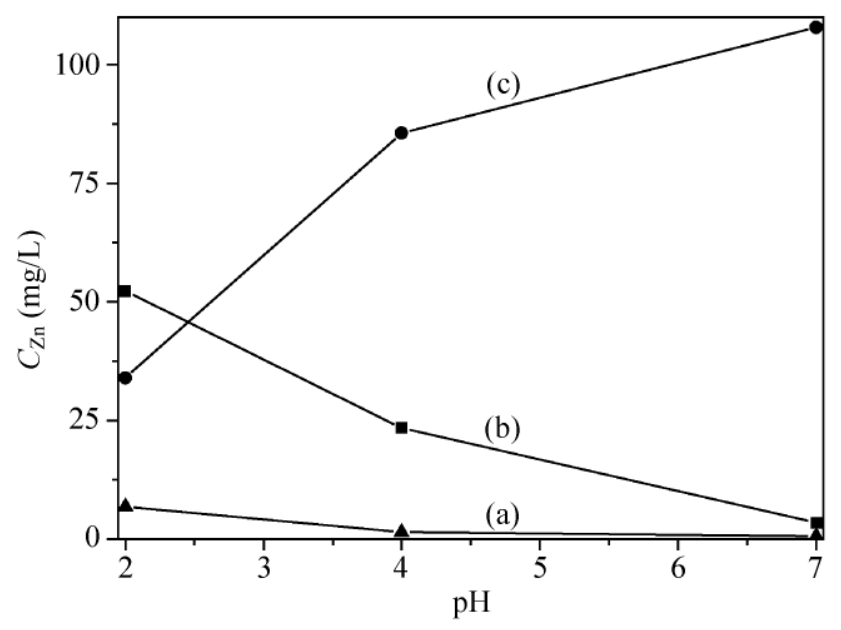

Figure 10 The release curves of $\mathrm{Zn}$ (II) ions from as-obtained zinc silicates as a function of $\mathrm{pH}$ value: (a) hollow spheres; (b) nanowires; (c) membranes

Table 2 Concentration of $\mathrm{Zn}(\mathrm{II})$ ion in the solutions after ion exchange

\begin{tabular}{cccc}
\hline \multirow{2}{*}{ Ions } & \multicolumn{3}{c}{ Concentration of $\mathrm{Zn}($ II $)(\mathrm{mg} / \mathrm{L})$} \\
\cline { 2 - 4 } & Hollow spheres & Nanowires & Membranes \\
\hline $\mathrm{Pb}($ II) & 8.73 & 44.55 & 27.05 \\
$\mathrm{Cd}($ II $)$ & 0.43 & 4.99 & 9.96 \\
$\mathrm{Cr}($ II $)$ & 84.38 & 363.00 & 104.20 \\
$\mathrm{Fe}($ II $)$ & 192.73 & 407.20 & 171.20 \\
\hline
\end{tabular}


experiment. This suggests that $\mathrm{Zn}$ (II) ions in both nanowires and membranes have exchanged with $\mathrm{Cr}$ (III) and $\mathrm{Fe}$ (III) ions. Additionally, after stirring the hollow spheres with $\mathrm{Cr}$ (III) and $\mathrm{Fe}$ (III) ions, the values of $C_{Z n}$ (Table 2) are higher than the value $(6.810 \mathrm{mg} / \mathrm{L})$ in the control experiment, which indicates that $\mathrm{Zn}$ (II) ions are partly substituted by $\mathrm{Cr}$ (III) or $\mathrm{Fe}$ (III) ions. Furthermore, the values of $C_{\mathrm{Zn}}$ using nanowires as absorbent are much lower than the values of $C_{\mathrm{Zn}}$ for the hollow spheres and the removal capacity of hollow spheres is higher than that of nanowires. This indicates that some $\mathrm{Cr}$ (III) and $\mathrm{Fe}$ (III) ions insert into the vacant sites of hollow spheres and ion adsorption is also an important factor in the removal of $\mathrm{Cr}$ (III) and $\mathrm{Fe}$ (III) ions by the hollow spheres.

To investigate the desorption process, the ionexchanged zinc silicate absorbents $(80 \mathrm{mg})$ were dispersed in a stirred concentrated solution of $\mathrm{Zn}(\mathrm{II})$ ions ( $50 \mathrm{~mL}$ of $0.2 \mathrm{~mol} / \mathrm{L}$ solution) for $3 \mathrm{~h}$. The absorbents were centrifuged and washed with deionized water and ethanol, and then dried at $70{ }^{\circ} \mathrm{C}$ in air. $\mathrm{Fe}(\mathrm{III})$ ions were chosen as an example, and the hollow spheres were used as absorbents in repeated cycles. After ion exchange for $3 \mathrm{~h}$, an $\mathrm{Fe}$ (III) solution with an initial concentration of $221.35 \mathrm{mg} / \mathrm{L}$ remained colorless after addition of $0.01 \mathrm{~mol} / \mathrm{L} \mathrm{SCN}^{-}$ions after the second cycle, which indicated that $\mathrm{Fe}(\mathrm{III})$ ions were almost completely removed (Fig. 11).

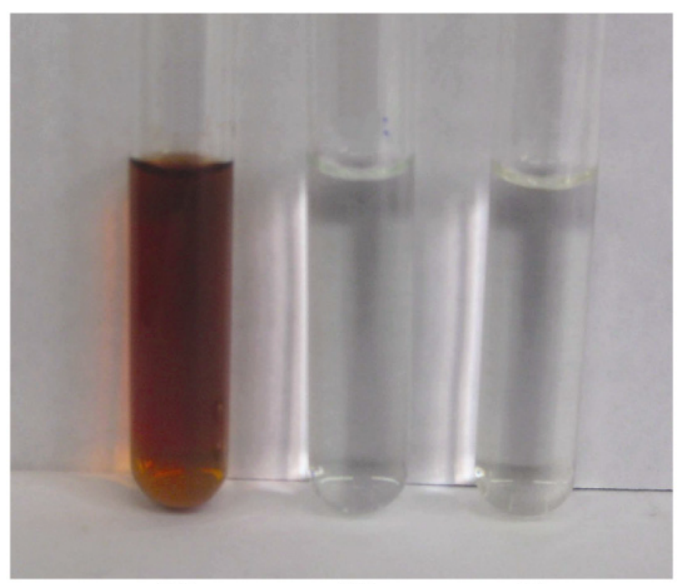

(a)

(b)

(c)

Figure 11 The removal capacity of zinc silicate hollow spheres for $\mathrm{Fe}(\mathrm{III})$ ions in repeated cycles: (a) Initial $\mathrm{Fe}(\mathrm{III})$ solution (221.35 mg/L) after addition of $\mathrm{SCN}^{-}$ions; (b) after the first cycle; (c) after the second cycle

\section{Conclusions}

Amorphous and crystalline zinc silicates with controllable dimensionalities and well-defined shapes have been synthesized in different systems. 0-D hollow spheres with an amorphous structure were obtained in an ethanol/PEG system. 1-D nanowires and 2-D membranes with crystalline structures were prepared in aqueous systems. The capacity of the as-obtained zinc silicate samples for removal of metal ions has been studied. Compared with magnesium silicate hollow spheres, amorphous zinc silicate hollow spheres exhibit better removal capacity, with the capacity of removal for $\mathrm{Pb}(\mathrm{II})$ ions being higher by a factor of two. Amorphous hollow spheres showed the best removal ability for all the metal ions studied. The removal abilities of crystalline 1-D nanowires and 2-D membranes were found to be dependent on the oxidation number of the target metal ion. In general, nanowires showed better removal capacity for trivalent ions, especially for Fe(III) ions, while 2-D membranes exhibited better removal capacity for divalent ions.

\section{Acknowledgements}

This work was supported by National Natural Science Foundation of China (NSFC) (No. 20725102), the Fok Ying Tung Education Foundation (No. 111012) and the State Key Project of Fundamental Research for Nanoscience and Nanotechnology (No. 2006CB932301).

Electronic Supplementary Material: Supplementary material is available in the online version of this article at http://dx.doi.org/10.1007/s12274-010-0019-3 and is accessible free of charge. It contains evidence in support of the proposed mechanism of formation of zinc silicate hollow spheres (TEM and XRD data), TEM, SEM and XRD data for the nanorods (obtained with a $\mathrm{Zn:Si}$ ratio of 2:1 in the presence of $\mathrm{NaCl}$ ), the EDS of zinc silicate nanowires and the XRD pattern of the rod-like product obtained with a $\mathrm{Zn}: \mathrm{Si}$ ratio of 2:1.5 without addition of $\mathrm{NaCl}$.

Open Access: This article is distributed under the terms of the Creative Commons Attribution Noncommercial License which permits any noncommercial use, 
distribution, and reproduction in any medium, provided the original author(s) and source are credited.

\section{References}

[1] Mohan, D.; Singh, K. P. Single- and multi-component adsorption of cadmium and zinc using activated carbon derived from bagasse-An agriculture waste. Water Res. 2002, 36, 2304-2318.

[2] Namasivayam, C.; Kavitha, D. Removal of Congo Red from water by adsorption onto activated carbon prepared from coir pith, an agriculture solid waste. Dyes Pigments 2002, $54,47-58$.

[3] Mohan, D.; Singh, K. P.; Singh, V. K. Trivalent chromium removal from wastewater using low cost activated carbon derived from agricultural waste material and activated carbon fabric cloth. J. Hazard. Mater. B 2006, 135, 280-295.

[4] Zhang, D. H.; Ryu, K. M.; Liu, X. L.; Polikarpov, E.; Ly, J.; Tompson, M. E.; Zhou, C. W. Transparent, conductive, and flexible carbon nanotube films and their application in organic light-emitting diodes. Nano Lett. 2006, 6, 1880-1886.

[5] Tombros, N.; Buit, L.; Arfaoui, I.; Tsoufis, T.; Gournis, D.; Trikalitis, P. N.; Molen, S. J.; Rudolf, P.; Wees, B. J. Charge transport in a single superconducting tin nanowire encapsulated in a multiwalled carbon nanotube. Nano Lett. 2008, 8, 3060-3064.

[6] Li, W. X.; Li, Y.; Chen, R. H.; Zeng, R.; Lu, L.; Zhang, Y.; Tomsic, M.; Rindfleisch, M.; Dou, S. X. Increased superconductivity for CNT doped $\mathrm{MgB}_{2}$ sintered in $5 \mathrm{~T}$ pulsed magnetic field. IEEE Trans. Appl. Supercon. 2009, 19, 2752-2755.

[7] Kasumov, A. Y.; Deblock, R.; Kociak, M.; Reulet, B.; Bouchiat, H.; Khodos, I. I.; Gorbatov, Y. B.; Volkov, V. T.; Journet, C.; Burghard, M. Supercurrents through singlewalled carbon nanotubes. Science 1999, 284, 1508-1511.

[8] Hwang, G. L.; Hwang, K. C.; Shieh, Y. T.; Lin, S. J. Preparation of carbon nanotube encapsulated copper nanowires and their use as a reinforcement for $\mathrm{Y}-\mathrm{Ba}-\mathrm{Cu}-\mathrm{O}$ superconductors. Chem. Mater. 2003, 15, 1353-1357.

[9] Bandow, S; Numao, S; Iijima, S. Variable-range hopping conduction in the assembly of boron-doped multiwalled carbon nanotubes. J. Phys. Chem. C. 2007, 111, 11763-11766.

[10] Wang, J. J.; Yin, G. P.; Liu, H.; Li, R. Y.; Flemming, R. L.; Sun, X. L. Carbon nanotubes supported Pt-Au catalysts for methanol-tolerant oxygen reduction reaction: A comparison between $\mathrm{Pt} / \mathrm{Au}$ and PtAu nanoparticles. J. Power Sources 2009, 194, 668-673.

[11] Liu, Z.; Tabakman, S.; Welsher, K.; Dai, H. J. Carbon nanotubes in biology and medicine: In vitro and in vivo detection, imaging and drug delivery. Nano Res. 2009, 2, 85-120.

[12] Girishkumar, G.; Hall, T. D.; Vinodgopal, K.; Kamat, P. V. Single wall carbon nanotube supports for portable direct methanol fuel cells. J. Phys. Chem. B 2006, 110, 107-114.

[13] Kongkanand, A.; Kuwabata, S.; Girishkumar, G.; Kamat, P. Single-wall carbon nanotubes supported platinum nanoparticles with improved electrocatalytic activity for oxygen reduction reaction. Langmuir 2006, 22, 2392-2396.

[14] Asuri, P.; Karajanagi, S. S.; Sellitto, E.; Kim, D. Y.; Kane, R. S.; Dordick, J. S. Water-soluble carbon nanotube-enzyme conjugates as functional biocatalytic formulations. Biotechnol. Bioeng. 2006, 95, 804-811.

[15] Yu, D. C.; Lupton, E. M.; Liu, M.; Liu, W.; Liu, F. Collective magnetic behavior of graphene nanohole superlattices. Nano Res. 2008, 1, 56-62.

[16] Ying, J. Y.; Mehnert, C. P.; Wong, M. S. Synthesis and applications of supramolecular-templated mesoporous materials. Angew. Chem. Int. Ed. 1999, 38, 56-77.

[17] Stein, A.; Melde, B. J.; Schroden, R. C. Hybrid inorganicorganic mesoporous silicates-Nanoscopic reactors coming of age. Adv. Mater. 2000, 12, 1403-1419.

[18] Pai, R. A.; Humayun, R.; Schulberg, M. T.; Sengupta, A.; Sun, J. N.; Watkins, J. J. Mesoporous silicates prepared using preorganized templates in supercritical fluids. Science 2004, 303, 507-510.

[19] Fotopoulos, A. P.; Triantafyllidis, K. S. Ethylene epoxidation on Ag catalysts supported on non-porous, microporous and mesoporous silicates. Catal. Today 2007, 127, 148-156.

[20] Wang, X.; Zhuang, J.; Chen, J.; Zhou, K. B.; Li, Y. D. Thermally stable silicate nanotubes. Angew. Chem. Int. Ed. 2004, 43, 2017-2020.

[21] Tsvelikhovsky, D.; Pessing, D.; Avnir, D.; Blum, J. Forcing a cis-product by matrix imprinting: Heck reaction catalyzed by palladium acetate entrapped within cis-imprinted sol-gel derived silicates. Adv. Synth. Catal. 2008, 350, 2856-2858.

[22] Marin-Astorga, N.; Pecchi, G.; Pinnavaia, T. J.; Alvez-Manoli, G.; Reyes, P. Mesostructured silicas as supports for palladium-catalyzed hydrogenation of phenyl acetylene and 1-phenyl-1-hexyne to alkenes. J. Mol. Catal. A: Chem. 2006, 247, 145-152.

[23] Kalinkin, A. M.; Kalinkina, E. V.; Zalkind, O. A. Mechanosorption of carbon dioxide by $\mathrm{Ca}$ - and $\mathrm{Mg}$-containing silicates and alumosilicates Sorption of $\mathrm{CO}_{2}$ and structurerelated chemical changes. Colloid J. 2009, 71, 185-192.

[24] Katayama, S.; Yamada, N.; Awano, M. Preparation of silicates using $\mathrm{HSi}\left(\mathrm{OC}_{2} \mathrm{H}_{5}\right)_{3}$ and their $\mathrm{NO}_{x}$-adsorption behavior. $J$. Sol-Gel Sci. Technol. 2004, 32, 311-316.

[25] Takesue, M.; Suino, A.; Hakuta, Y.; Hayashi, H.; Smith, R. 
L, Jr. Formation mechanism and luminescence appearance of Mn-doped zinc silicate particles synthesized in supercritical water. J. Solid State Chem. 2008, 181, 1307-1313.

[26] Wang, X.; Zhuang, J.; Peng, Q.; Li, Y. D. A water-ethanol mixed-solution hydrothermal route to silicates nanowires. $J$. Solid State Chem. 2005, 178, 2332-2338.

[27] Xiong, L. M.; Shi, J. L.; Gu, J. L.; Shen, W. H.; Dong, X. P.; Chen, H. R.; Zhang, L. X.; Gao, J. H.; Ruan, M. L. Directed growth of well-aligned zinc silicate nanowires along the channels of surfactant-assembled mesoporous silica. Small 2005, 1, 1044-1047.

[28] Wan, J. X.; Chen, X. Y.; Wang, Z. H.; Mu, L.; Qian, Y. T. One-dimensional rice-like Mn-doped $\mathrm{Zn}_{2} \mathrm{SiO}_{4}$ : Preparation, characterization, luminescent properties and its stability. $J$. Cryst. Growth 2005, 280, 239-243.

[29] Wang, H. F.; Ma, Y. Q.; Yi, G. S.; Chen, D. P. Synthesis of Mn-doped $\mathrm{Zn}_{2} \mathrm{SiO}_{4}$ rodlike nanoparticles through hydrothermal method. Mater. Chem. Phys. 2003, 82, 414-418.

[30] Zeng, J. H.; Fu, H. L.; Lou, T. J.; Yu, Y.; Sun, Y. H.; Li, D. Y. Precursor, base concentration and solvent behavior on the formation of zinc silicate. Mater. Res. Bull. 2009, 44, 1106-1110.

[31] Wan, J. X.; Wang, Z. H.; Chen, X. Y.; Mu, L.; Yu, W. C.; Qian, Y. T. Controlled synthesis and relationship between luminescent properties and shape/crystal structure of
$\mathrm{Zn}_{2} \mathrm{SiO}_{4}: \mathrm{Mn}^{2+}$ phosphor. J. Lumin. 2006, 121, 32-38.

[32] Lou, T. J.; Zeng, J. H.; Lou, X. D.; Fu, H. L.; Wang, Y. F.; Ma, R. L.; Tong, L. J.; Chen, Y. L. A facile synthesis to $\mathrm{Zn}_{2} \mathrm{SiO}_{4}: \mathrm{Mn}^{2+}$ phosphor with controllable size and morphology at low temperature. J. Colloid Interface Sci. 2007, 314, 510-513.

[33] Zhong, L. S.; Hu, J. S.; Liang, H. P.; Cao, A. M.; Song, W. G.; Wan, L. J. Self-assembled 3D flowerlike iron oxide nanostructures and their application in water treatment. $A d v$. Mater. 2006, 18, 2426-2431.

[34] Hu, J. S.; Zhong, L. S.; Song, W. G.; Wan, L. J. Synthesis of hierarchically structured metal oxides and their application in heavy metal ion removal. Adv. Mater. 2008, 20, 2977-2982.

[35] Peng, X. J.; Luan, Z. K.; Ding, J.; Di, Z. C.; Li, Y. H.; Tian, B. H. Ceria supported on carbon nanotubes for the removal of arsenate from water. Mater. Lett. 2005, 59, 339-403.

[36] Yang, D. J.; Zheng, Z. F.; Liu, H. W.; Zhu, H. Y.; Ke, X. B.; $\mathrm{Xu}, \mathrm{Y}$; $\mathrm{Wu}, \mathrm{D}$.; Sun, Y. Layered titanate nanofibers as efficient adsorbents for removal of toxic radioactive and heavy metal ions from water. J. Phys. Chem. C 2008, 112, 16275-16280.

[37] Zhuang, Y.; Yang, Y.; Xiang, G. L.; Wang, X. Magnesium silicate hollow nanostructures as highly efficient absorbents for toxic metal ions. J. Phys. Chem. C 2009, 113, 1044110445 . 